\title{
Identificando posible Cráter de impacto en Gracias a Dios mediante teledetección
}

J. Valentín Mauri

\section{Resumen}

La Laguna Liwa está ubicada en el Municipio de Puerto Lempira, Depto. de Gracias a Dios a $15^{\circ} 15^{\prime} 06^{\prime \prime}$ latitud norte y $83^{\circ} 34^{\prime} 07^{\prime \prime}$ longitud oeste. Tiene un diámetro aproximado de $3.2 \mathrm{Km}$. Ha sido objeto de escrutinio mediante Teledetección, que es la utilización de la información multi-espectral que los diferentes satélites dedicados a la observación de la superficie terrestre nos brindan. Mediante el uso de software especializado para el procesamiento digital de imágenes en sus diferentes bandas y el uso de datos de radar para la creación de modelos de elevación digital es posible reconocer, si las condiciones de la superficie lo permiten, los diferentes rasgos distintivos que deja en la corteza continental un evento de impacto de asteroide que penetra la atmósfera a híper velocidad. La laguna Liwa, que presenta una estructura de contorno circular, rasgo propio de un cráter de impacto, nos ha brindado la posibilidad de realizar un estudio preliminar mediante Teledetección. No se descarta si la estructura en mención es en contexto, un potencial candidato a ser identificado como cráter de impacto.

Palabras Clave: Teledetección, craterismo de impacto, modelo de elevación digital, pantanos.

\section{Abstract}

The Liwa Lagoon is located in the Municipality of Puerto Lempira, Department of Gracias a Dios at $15^{\circ} 15$ ' $06^{\prime \prime}$ north latitude and $83^{\circ} 34^{\prime} 07^{\prime \prime}$ west longitude. It has an approximate diameter of $3.2 \mathrm{~km}$. It has been scrutinized by means of Remote Sensing, which is the use of the multi-spectral information that the different satellites dedicated to the observation of the Terrestrial surface gave us. Through the use of specialized software for the digital processing of images in their different 
bands and the use of radar data for the creation of digital elevation models it is possible to recognize, if the surface conditions allow it, the different distinguishing features that leaves In the continental crust an asteroid impact event that penetrates the atmosphere at high velocity. The Liwa lagoon which has a circular shape, characteristic of an impact crater, has given us the possibility of carrying out a preliminary study by means of Remote Sensing. It is not ruled out if the structure in mention, in context, is a potential candidate to be identified as impact crater.

Keywords: Remote Sensing, Impact cratering, Digital elevation model, wetlands.

J.Valentín Mauri, (jose.mauri@unah.edu), Depto. de Astronomía y Astrofísica. Universidad Nacional Autónoma de Honduras.

Fecha de recepción: 25 de agosto de 2016, fecha de aprobación: 3 de julio de 2017. 


\section{INTRODUCCIŐN}

El objetivo de la teledetección orientada al craterismo de impacto es proporcionar información útil sobre una posible estructura de impacto en una superficie planetaria previo a una investigación de campo, recolección de muestras o dado el caso donde el acceso puede ser limitado. El principio básico consiste en la recolección, la comprensión y el uso de los datos adquiridos como resultado de la interacción entre la materia (i.e. roca o superficie) y la energía electromagnética (e.g. longitudes de onda infrarrojas). Un conjunto de datos y técnicas de teledetección se han utilizado para determinar: (1) Geología; (2) La morfometría altimetría y topografía; (3) La composición mineral; (4) Las propiedades físicas (p.e. tamaño de partículas, inercia térmica). Diferentes regiones de longitud de onda, como también un conjunto de datos derivados y técnicas de procesamiento de datos pueden ser utilizados para determinar una 0 varias de las propiedades de superficie antes mencionadas con aplicaciones al estudio de cráteres de impacto (Wright, Tornabene \& Ramsey, 2012).

La fotogeología es el uso de datos aéreos u orbitales para ver e interpretar rasgos geológicos y geomorfológicos como los relieves montañosos, afloramientos rocosos, plegamientos y fallas de la corteza continental, campo de la geología estructural. Además, se ha utilizado para la evaluación de cambios dinámicos debido a eventos naturales como las erupciones volcánicas.

En el campo de las ciencias planetarias, la fotogeología, o análisis de imágenes, se ha utilizado para buscar la distintiva estructura circular de un cráter de impacto, asimismo de terrazas y picos centrales dentro de los cráteres grandes y complejos. Varias estructuras de impacto se han encontrado con este método (e.g., Folco et.al., 2010, 2011). Sin embargo, la teledetección por sí sola no puede proporcionar una evidencia definitiva para determinar si es un cráter de impacto, ya que muchas estructuras circulares pueden estar formadas por otros procesos geológicos como, por ejemplo; las dolinas, formaciones kársticas, diapiros salinos y volcanes. (Wright et. al., 2012).

Técnicas de teledetección como el LIDAR y el uso de altímetros de laser visible se han utilizado para la creación de un modelo topográfico de la superficie, el llamado modelo de elevación digital (DEM, por sus siglas en inglés). Uno de los usos principales de estos datos topográficos, particularmente con respecto a aplicaciones planetarias para cráteres de impacto, es la medida de los aspectos morfométricos, tales como profundidad, diámetro, volumen del relleno del cráter y varios aspectos o características del eyecta del cráter (Stewart y Valiant , 2006). 
Las propiedades físicas como la rugosidad de la superficie y la composición mineral pueden ser determinados mediante el análisis de la interacción de ciertos rangos del espectro electromagnético con los materiales de la superficie. Mediante datos multiespectrales, hay limitadas combinaciones de colores que se pueden hacer en una escena para enfatizar la variabilidad espectral mineral y litológica. La inspección individual de bandas es necesaria para determinar qué áreas están afectadas por las absorciones a una longitud de onda en particular. Al notar qué bandas muestran la mayor variabilidad, se puede hacer un mapa espectral de primer orden colocando tres de estas bandas en el rojo, verde y azul (R-V-A) (Wright et. al., 2012).

Por medio de la comparación de imágenes satelitales de distintas combinaciones espectrales de los cráteres de impacto tanto de la Tierra como de los demás planetas rocosos del sistema solar es posible determinar descriptivamente las huellas o rasgos característicos que deja un fenómeno de impacto de meteorito en la corteza continental.

El estudio de cráteres de impacto terrestres nos brinda una herramienta fundamental para la comprensión de la formación y evolución del Sistema Solar. Cada cráter de impacto en la Tierra tiene sus propias y únicas características, y nos ayuda a comprender los procesos de impacto y su importancia (Koeberl, 2004).

Es necesario el uso de softwares especializados para el procesamiento digital de imágenes en sus diferentes bandas. En esta investigación se utilizaron el TerrSet Geospatial Monitoring and Modeling System y el 3DEM de Visualization Software LLC (Digital elevation Model). El propósito del procesamiento digital de imágenes es el de resaltar elementos que son difíciles de percibir o no se pueden distinguir directamente en una imagen convencional (true-color). Se utilizaron los datos del ASTER (Advanced Spaceborne Thermal Emission and Reflection Radiometer), El Landsat 4-5 TM (Thematic Mapper), EL Landsat 7-8 ETM (Enhanced Thematic Mapper) y y los datos de elevación digital obtenidos del SRTM (Shuttle Radar Topography Mission).

En el territorio centroamericano aún no se ha reportado el hallazgo de un cráter de impacto a la base de datos de impactos de la Tierra. (http://www.passc.net/ EarthlmpactDatabase/index.html.) 
Esta investigación está orientada a la búsqueda de un posible astroblema en territorio hondureño.

\section{METODOLOGÍA}

La metodología se centra en técnicas de teledetección y geología comparativa mediante el uso imágenes satelitales de distintas combinaciones espectrales. A continuación, se describen los pasos seguidos:

1. Definición de características distintivas en un astroblema o cráter de impacto. Entre las características distintivas a definir según las diferentes propiedades que presentan las superficies terrestres sometidas a un impacto y la variada composición mineral que surge de acorde al rango del espectro electromagnético están:

- Las propiedades y características detectables en el Visible al infrarrojo cercano (VNIR) al infrarrojo de onda corta (SWIR).

- Propiedades detectables en el Infrarrojo térmico (TIR), incluyendo del infrarrojo medio al infrarrojo lejano.

- Propiedades y características que resultan del Realce espectral, como el eyecta del cráter.

- Rugosidad y elevación de la superficie a partir de imágenes en microondas (i.e. Radar).

2. Descarga sistemática de datos espectrales de los archivos de la agencia estadounidense, U.S. Geological Survey (USGS) y Earth Resources Observation \& Science Center (EROS), según el tipo y nombre del orbitador, satélite y/o radar.

3. Visita de campo: Esta actividad consistió en un recorrido por el borde y el perímetro circundante de la Laguna Liwa lo que permitió lograr un reconocimiento de los diferentes tipos de vegetación de la zona. Además, se ha podido constatar la presencia de sedimentación palustre y lacustre en el área (Aluvión Cuaternario). 
4. Análisis de la información mediante el uso del software especializado para el procesamiento digital de imágenes en sus diferentes bandas. P.e. el TerrSet Geospatial Monotoring and Modeling System y el 3DEM de Visualization Software LLC (Digital elevation Model).

\section{Definición de características distintivas}

La zona de la laguna Liwa es un humedal. Se encontró tanto zonas parcialmente inundadas como zonas con grado de saturación muy alto. No hay presencia de una superficie rocosa necesaria para un análisis litológico y mineralógico, debido al enterramiento de capa tras capa de sedimentos típicos de los medios palustres formados por la acumulación de materia orgánica casi exclusivamente de origen vegetal además de grava, arena, arcilla y limos.

Con tasas anuales de precipitación de 2.8-3.4 m./año (CIDBIMENA, Análisis de los valores promedio de lluvia anual en Honduras por cada departamento,1966-1985) estas tierras bajas representan una de las regiones más húmedas de la Tierra. Las Ilanuras aluviales de la costa de la Mosquitia se formaron durante el Cenozoico tardío sobre una masa coalescente de arena deltaica y depósitos de grava derivados de la erosión de las tierras altas del interior con dirección hacia el oeste del territorio. Estos depósitos pueden alcanzar un espesor de hasta $4500 \mathrm{~m}$. en algunas áreas (Rogers, R.D., 1998).

El aumento del nivel del mar durante el Holoceno ha transferido la deposición del abanico distal en alta mar, a una serie de deltas costeros más pequeños a lo largo de la costa moderna. La interacción constante entre el desplazamiento de los cursos fluviales, la fluctuación del nivel del mar y la migración de los deltas ha sido fundamental a lo largo del Cenozoico tardío en la conformación de las amplias llanuras aluviales de la costa de la Mosquitia (Rogers, R.D. Incised meanders of the Río Patuca, stream piracy and landform development of the La Mosquitia, Central America, 1998, pp. 92.)

Debido a esto se procedió a distinguir y reconocer los tipos de vegetación presentes en la zona mediante el uso de diferentes combinaciones espectrales, y relacionar la diferencia de elevación del terreno circundante con los diferentes tipos de vegetación. Se analizó la elevación del lugar por medio de imágenes DEM (Digital Elevation Model). Datos extraídos de la agencia estadounidense, USGS (United States Geological Survey). 
A continuación, se describen las características fotométricas de las bandas usadas por landsat 7 en la Tabla 1. Además, se muestran algunas combinaciones comunes de estas bandas aplicadas a Landsat 7. El orden de combinación es rojo, verde, azul (RVA):

Tabla 1. Características fotométricas de las Bandas del Satélite Landsat 7.

\begin{tabular}{|c|c|c|}
\hline Landsat 7 (ETM+ sensor) & $\begin{array}{c}\text { Longitud de onda } \\
\text { (micrometros) }\end{array}$ & $\begin{array}{c}\text { Rango del espectro } \\
\text { electromagnetico. }\end{array}$ \\
\hline Band 1 & $0.45-0.515$ & azul-verde \\
\hline Band 2 & $0.525-0.605$ & rojo \\
\hline Band 3 & $0.63-0.69$ & Infrarrojo cercano \\
\hline Band 4 & $0.75-0.90$ & Infrarrojo medio \\
\hline Band 5 & $1.55-1.75$ & Infrarrojo termal \\
\hline Band 6 & $10.40-12.50$ & Infrarrojo medio \\
\hline Band 7 & $2.09-2.35$ & \\
\hline
\end{tabular}

Tomado de http://gif.berkeley.edu/documents/Landsat\%20Band\%20Information.pdf.

\section{Combinaciones comunes de bandas usadas en Landsat $7^{1:}$ :}

3,2,1 RVA: Esta composición de color es lo más cercano a una imagen a color verdadero que podemos obtener con el Landsat ETM+ (Enhanced Thematic Mapper plus). Es útil para estudiar los hábitats acuáticos. La desventaja de este conjunto de bandas es que tienden a producir una imagen brumosa.

4,3,2 RVA: Es la composición estándar de "falso color". La vegetación aparece en tonos rojos, las zonas urbanas son de color azul cian, y los suelos varían de marrón oscuro a marrón claro. El hielo, la nieve y las nubes son blancos o cian claro. Los

\footnotetext{
${ }^{1}$ Tomado de http://web.pdx.edu/ emch/ip1/bandcombinations.html y de http://gif.berkeley.edu/documents/Landsat\%20 Band\%20Information.pdf
} 
árboles de coníferas aparecerán más en rojo oscuro que las maderas duras. Por lo general, los tonos rojos intensos indican hojas anchas y/o vegetación más sana, mientras que los rojos más claros representan praderas 0 áreas escasamente vegetadas.

4,5,3 RVA: Esta es más nítida que las dos imágenes anteriores porque las dos bandas de longitud de onda más cortas (bandas 1 y 2 ) no están incluidas. Diferentes tipos de vegetación pueden definirse más claramente y la interfaz tierra/agua es muy clara. Las variaciones en el contenido de humedad del suelo son evidentes con este conjunto de bandas. Esta es probablemente la combinación de bandas más común para imágenes Landsat.

7,4,2 RVA: La vegetación sana será de un verde brillante y puede saturar en temporadas de crecimiento intenso, las praderas aparecerán verdes, las áreas rosadas representarán el suelo estéril, las naranjas y los marrones representan áreas escasamente vegetadas. La vegetación seca será naranja y el agua será azul. Es útil para estudios geológicos, agrícolas y de humedales. Si hubiera algún incendio en esta imagen aparecerían rojos. Esta combinación se utiliza en las aplicaciones de gestión de incendios para el análisis posterior al incendio de zonas forestadas quemadas y no quemadas. Las praderas aparecen como verde claro.

5,4,1 RVA: Esta combinación de bandas tiene propiedades similares a la combinación $7,4,2$, sin embargo, es más adecuada para visualizar la vegetación agrícola.

\section{RESULTADO DE LOS DATOS DESCARGADOS DE USGS}

A continuación, se muestran varios ejemplos de imágenes satelitales que fueron analizadas con software especializado. De los DEM obtenidos mediante altimetría de radar se obtuvo el siguiente modelo de elevación digital: 


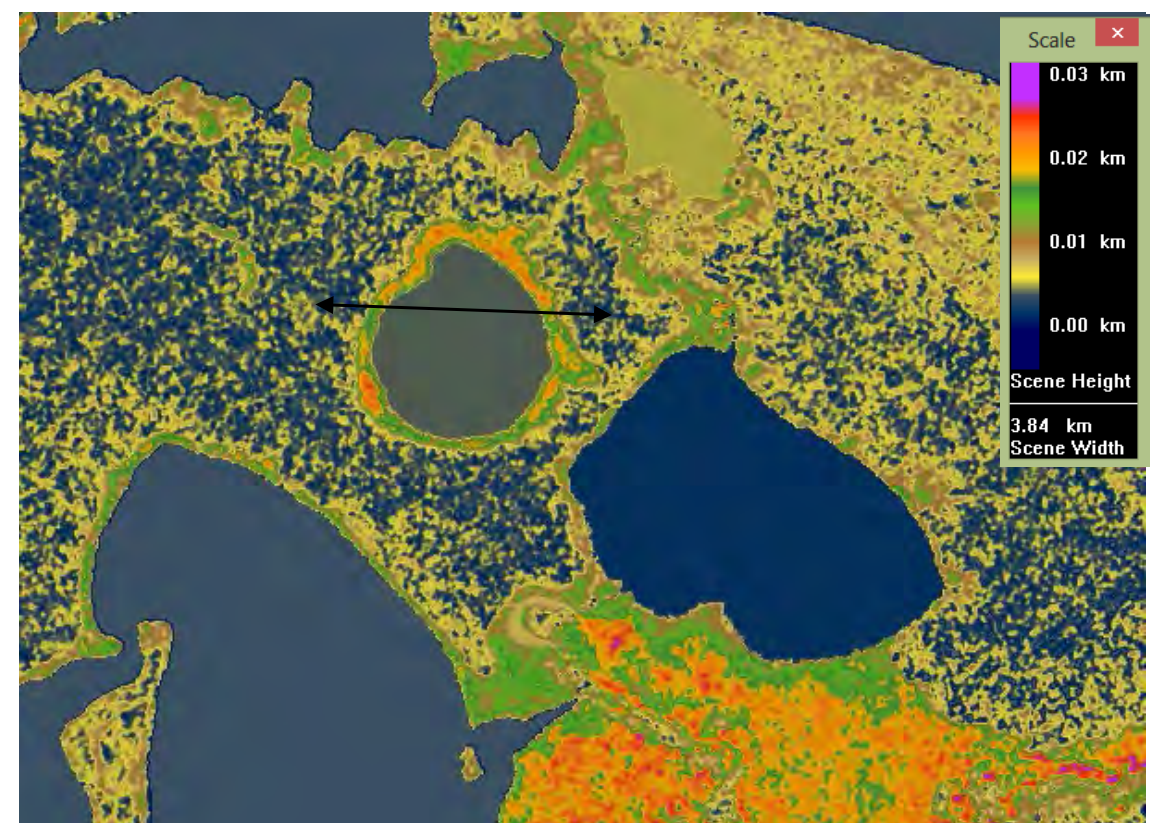

Figura 1.

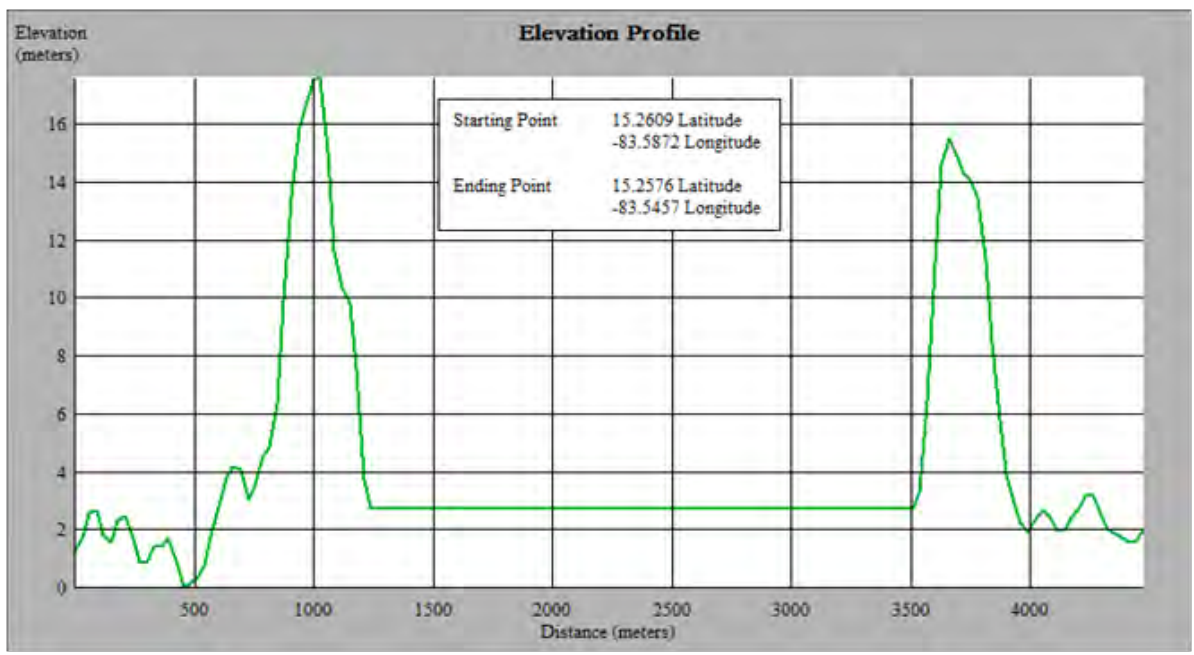

Figura 2. 
En la figura 1, se observa en tonos naranja y rojo las porciones más elevadas de la orilla de la laguna correspondientes a un bosque de madera dura. Son árboles de tronco grueso que alcanzan entre 12 y 19 metros de altura aproximadamente. Este tipo de bosque solo se encuentra en la orilla de la laguna y en zonas de mayor elevación. En la figura 2, correspondiente a la sección transversal de la laguna, el terreno circundante describe una elevación media de 2.00 m.s.n.m.(metros sobre el nivel del mar). Se observa una elevación de 17.00 y 15.50 m.s.n.m correspondiente a los bordes de la laguna. El espejo de agua presenta una elevación de 3.00 m.s.n.m.

La figura 3 es una combinación de las bandas 4,5,3 en RVA (Rojo Verde y Azul) Diferentes tipos de vegetación pueden ser claramente definidos y la interfaz tierra/ agua es muy clara. Las variaciones en el suelo saturado son evidentes con este conjunto de bandas.

En el margen de la laguna se observa una transición entre tres tipos de vegetación. En la orilla mostrando un color rojo medio tenemos un bosque de madera dura de hoja ancha muy denso, seguido por un color rojo claro correspondiente a arbustos y helechos de pantano finalizando con varios tonos de verde en la zona circundante de la laguna típicos del junco (grama de pantano). En la zona circundante a la laguna se puede apreciar unos tonos de café y azul oscuro correspondiente a zonas completamente saturadas de agua por encima del nivel de la capa vegetal.

En la llanura dominada por tonos verde se encuentran unas manchas de tonos rojos distribuidas en forma aleatoria que muestran elevaciones un poco mayores al terreno circundante. Vegetación diferente a la grama de pantano se observa en estas manchas, según visita de campo en su mayoría palma de pantano (Palmito). 


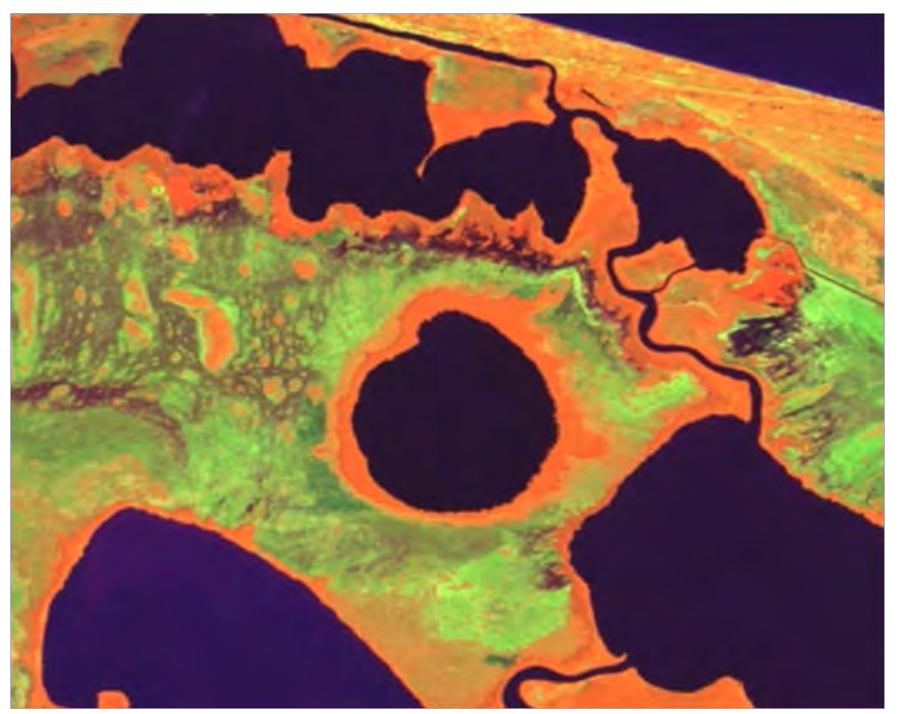

Figura 3.

La combinación de la figura 4, proporciona una interpretación "casi-natural" además de penetrar partículas atmosféricas y humo. Tiene propiedades similares a la combinación de las bandas 4,5,3 con la mayor diferencia de que ahora la vegetación es de tonos verde, con excepción del Junco (grama de pantano) que se muestran en tonos marrones.

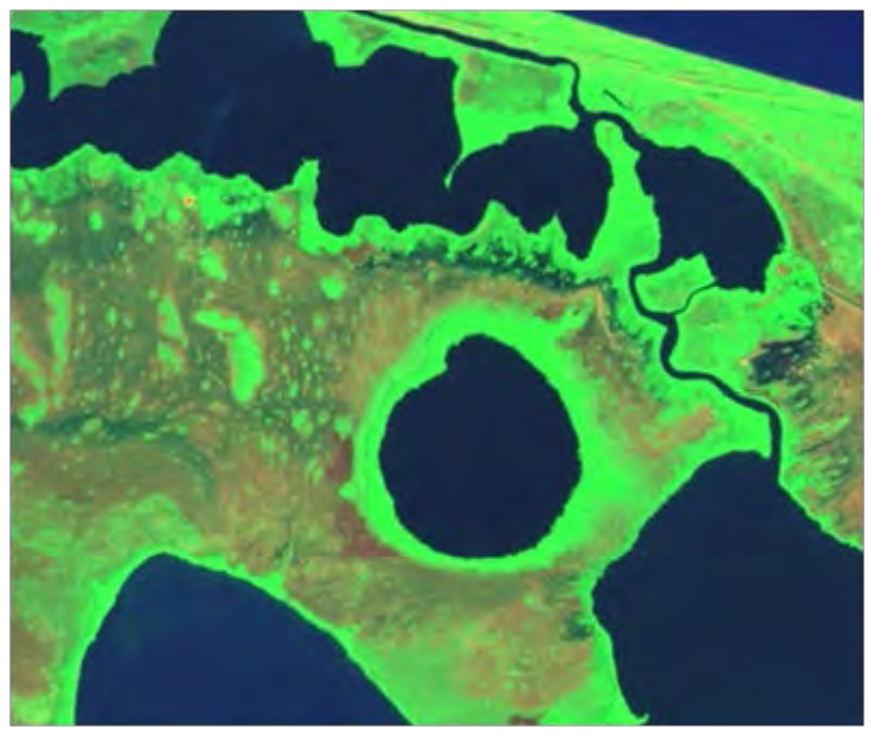

Figura 4. 
La composición de la figura 5, incluye el canal del infrarrojo cercano (banda 4) los límites entre el humedal y los cuerpos de agua son más claros. Diferentes tipos de vegetación aparecen muy evidentes. La grama de pantano aparece en tonos marrones y las zonas de humedal muestran un color azul oscuro.

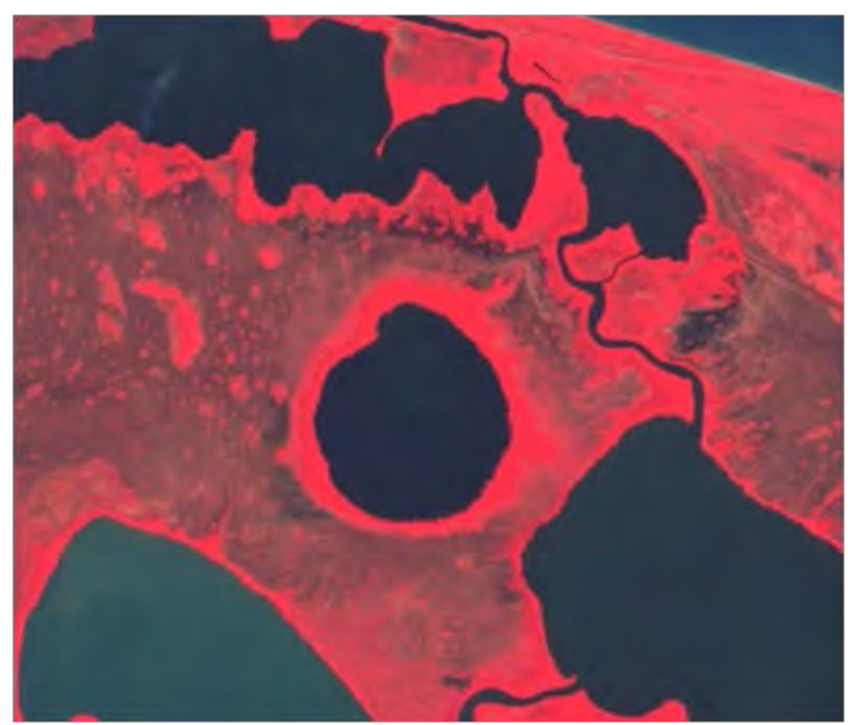

Figura 5.

En la combinación de la figura 6 , se observa en tonos café oscuro a veces azul oscuro las zonas parcialmente inundadas características de un pantano o humedal. El tipo de vegetación en tonos verde alrededor de la laguna sugiere una elevación poco mayor a la zona inundada, lo que podría sugerir la deposición de material con diferente elevación alrededor de la laguna similar a lo que ocurre durante el eyecta de material durante un evento de impacto. 


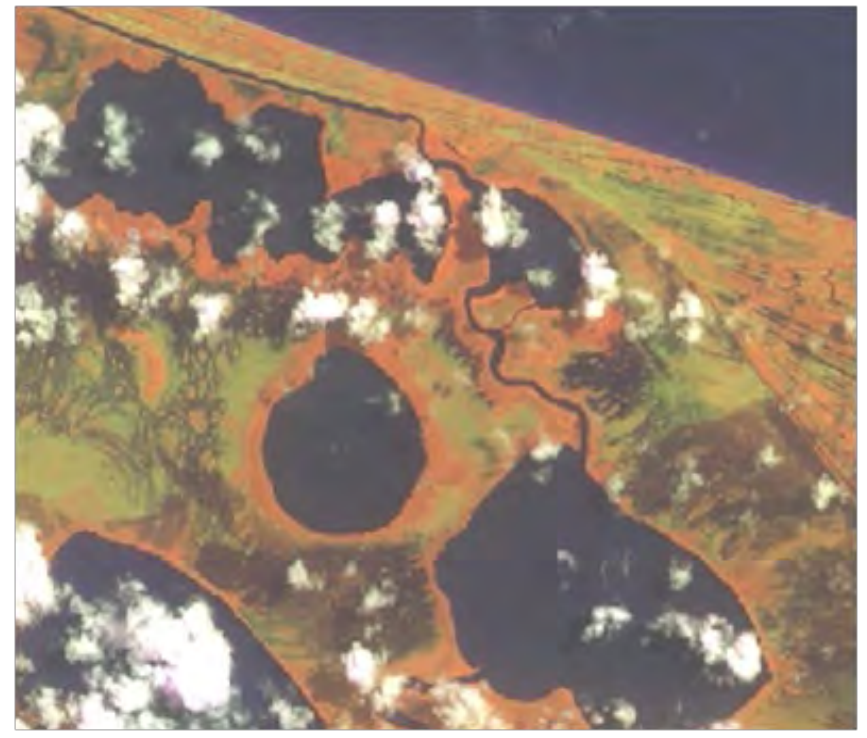

Figura 6.

\section{Visita de campo}

Mediante las visitas de campo se pudieron observar los diferentes tipos de vegetación en el borde y zona circundante de la laguna Liwa. Se enterró un bastón de 2 metros fácilmente en los sedimentos tipo palustre constatando las gruesas capas de sedimento que se han acumulado a través del tiempo. A continuación, se muestran las imágenes.

Para entrar a la laguna navegamos por el único canal existente al norte de Liwa hecho por habitantes de la zona para la pesca y la extracción de madera del bosque húmedo. Esta zona de manglares pertenece al borde de la Laguna de Cauquira, ubicada al norte de Liwa (Figura 7). No hay presencia de bosque de madera dura en este margen. Liwa es la única laguna de los alrededores que no posee un efluente natural. 


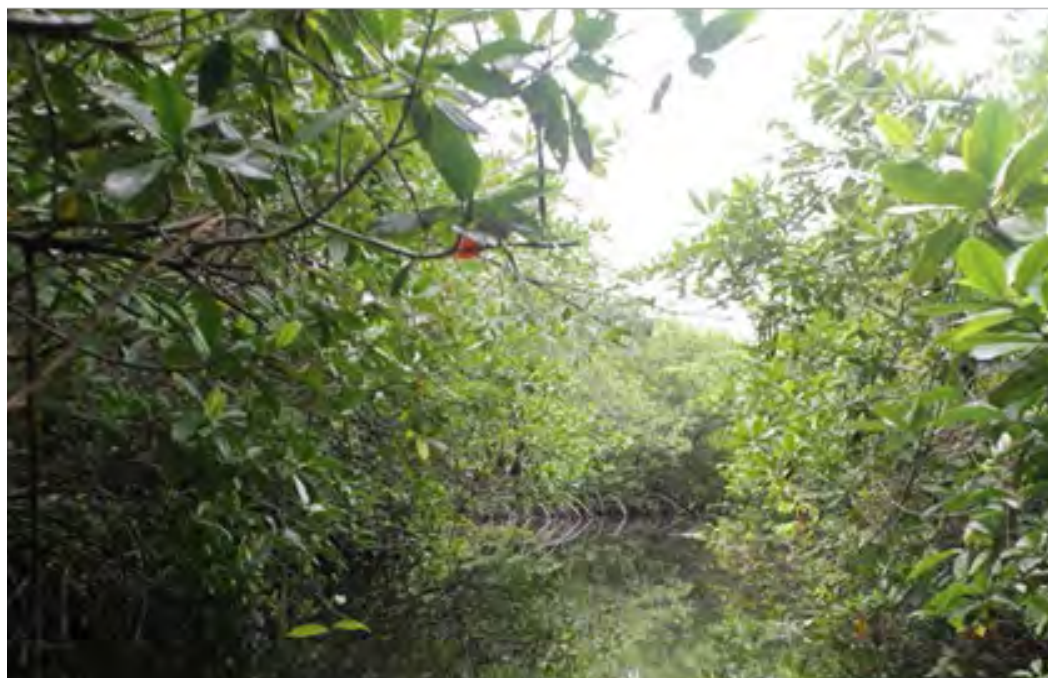

Figura 7.

La figura 8 es una imagen lograda desde un costado de la lancha con vista hacia la llanura norte. Se observan palmas de pantano (Palmito) a veces localizadas en pequeños promontorios y el junco o grama de pantano. Esta es la zona intermedia entre las lagunas Cauquira y liwa.

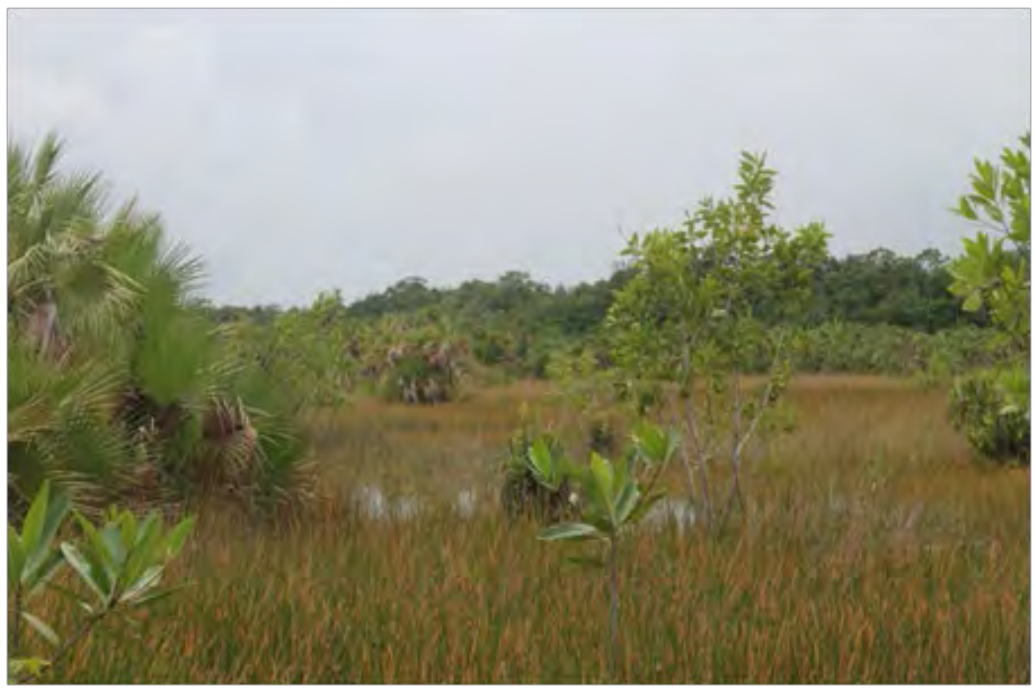

Figura 8. 
En el borde de la Laguna inmediatamente después del espejo de agua se observan arboles de madera dura y vegetación de hoja ancha, correspondiente al primer tipo de vegetación (Figura 9). Arboles con más de 10 metros de altura sugieren un suelo con una capacidad de soporte extra diferente al que ofrecen las zonas inundadas.

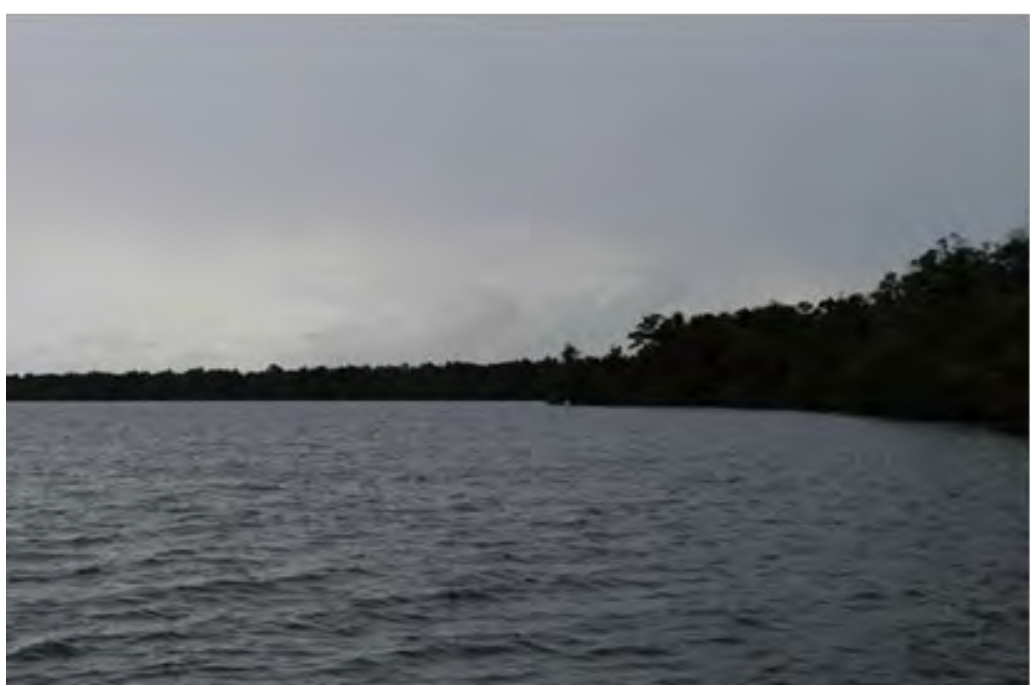

Figura 9.

Camino a la llanura sur, atravesamos la zona que corresponde al perímetro externo del borde de la laguna Liwa donde se observan helechos y palmitos (Figura 10). Es el segundo tipo de vegetación después del bosque de madera dura. 


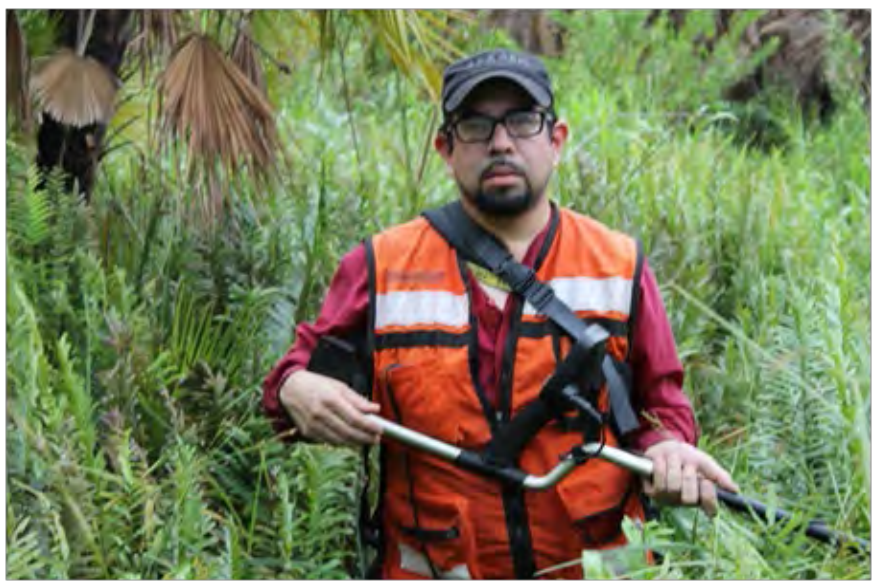

Figura 10.

En la Llanura Sur. Se observa Junco (grama de pantano) que es el tercer tipo de vegetación, con el nivel del agua aproximadamente a $35 \mathrm{~cm}$ sobre el nivel del suelo (Figura 11). Esta zona completamente saturada de agua corresponde a la llanura circundante de la Laguna Liwa.

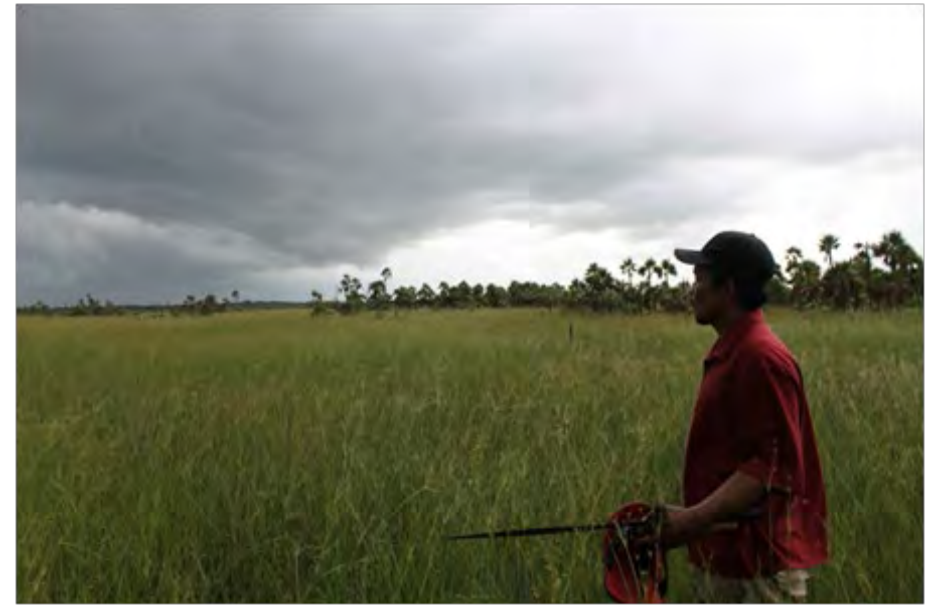

Figura 11. 


\section{DISCUSIÓN}

De los modelos de elevación digital se obtuvieron elevaciones mayores a 6.00 m.s.n.m en el área correspondiente al borde de la laguna. Elevaciones mayores a 10 metros sobre el nivel del mar son lecturas que han sido aumentadas por la cima de los árboles de madera dura que se localizan solo en la orilla de la Laguna. Es sugerente encontrar arboles de gran altura en el margen de la laguna, donde se observa que el terreno hace una disminución paulatina entre 6.50 a 5.00 hasta de entre 2.00 a 1.50 metros sobre el nivel del mar.

Junto a la observación de la disminución de elevación desde la orilla de la laguna hacia el perímetro externo se observa un cambio en el tipo de vegetación, desde arboles de gran tamaño hasta llegar al junco o gramilla de pantano respectivamente. Esto sugiere que la diferencia en especies vegetales se debe al desarrollo de las mismas en terrenos con diferentes grados de saturación hasta llegar a zonas completamente inundadas por una media aproximada de $35 \mathrm{~cm}$ de agua sobre la capa vegetal. No es normal encontrar zonas con una elevación mayor a 5.00 m.s.n.m. en las planicies que rodean la Laguna Liwa, ya que son el resultado de una sedimentación gradual y escalonada propia de un aluvión. Se reconocen pequeños islotes con una vegetación que consiste básicamente en palmitos en las planicies inundadas donde predomina el junco o la gramilla de pantano.

El observar elevaciones mayores solo en la orilla de la laguna requiere el esclarecimiento del proceso de formación geológica que causó una diferencia de elevación. La presencia de islotes con diferente vegetación en las planicies inundadas podría relacionarse con el mismo proceso que causó la diferencia de elevaciones en general. La búsqueda de evidencias litológicas requiere de un equipo de perforación avanzado.

\section{CONCLUSIONES}

Después de la visita de campo, del análisis de los datos obtenidos del Lansat 7 ETM, ASTER DEM y de la hoja cartográfica de la zona se obtuvieron las siguientes conclusiones:

- La zona de la Laguna Liwa es un humedal en toda su extensión. Estos son afectados por caudales fluviales de muy baja velocidad que permiten la 
deposición de sedimentos de forma escalonada y gradual en una escala geológica de miles de años.

- Según el mapa Geotectónico de Honduras elaborado por el Instituto Geográfico Nacional, la zona de la Laguna Liwa es un aluvión cuaternario. El aluvión del Cuaternario (Qal) se encuentra cubriendo los cauces de los arroyos y ríos principales. Consiste de material suelto constituido de arena, limo y arcilla, como resultado de la erosión de las rocas que afloran en el interior del territorio. Este material es transportado, tanto por las corrientes de los ríos Nakunta y Kruta como de la escorrentía fluvial de superficie, y es depositado sobre las llanuras de inundación perteneciente a la zona circundante de la Laguna Liwa.

- La laguna se encuentra localizada en un ambiente sedimentario lacustre y palustre que presenta sedimentos del tamaño del limo y la arcilla de un color negro. Son abundantes en materia orgánica en descomposición.

- El mecanismo geológico que causó la diferencia de elevaciones en la zona circundante de la laguna Liwa es cuestionable. No se descarta la posibilidad de considerar la Laguna Liwa como un posible candidato a ser identificado como cráter de impacto.

- Es necesario un estudio de las capas interiores mediante el uso de un Ensayo de Penetración Estándar de profundidad para determinar la composición de las diferentes capas de sedimento y la búsqueda del lecho rocoso, si es que este, se encuentra a poca profundidad.

- Si el lecho de roca está muy profundo, es necesario hacer un estudio de gravimetría (Otra técnica de teledetección) para determinar variaciones de densidad del lecho profundo, típicas de un metamorfismo de impacto.

- Se requiere la simulación de cráteres de impacto en áreas pantanosas con el propósito de definir una morfología tanto del eyecta que se forma alrededor del cráter como de los efectos que pueda causar la saturación del material, en la profundidad final del cráter y elevación del borde del mismo. 


\section{BIBLIOGRAFÍA}

- Christian Koeberl, 2004.Remote sensing studies of impact craters: how to be sure?. C. R. Geoscience 336 959-961

- Bottke, W.F., Melosh, H.J., 1996. Binary asteroids and the formation of doublet craters. Icarus 124, 372-391.

- Collins, G.S., Melosh, H.J., Marcus, R.A., 2005. Earth impact effects program: a web based computer program for calculating the regional environmental consequences of a meteoroid impact on earth. Meteorit. Planet. Sci. 40 (6), 817-840.

- John A. Grant, Christian Koeberl, Wolf Uwe Reimold, Peter H. Schultz, 1997. Gradation of the Roter Kamm impact crater, Namibia.

- Passey, Q., Melosh, H.J., 1980. The effects of atmospheric break-up on crater field formation. Icarus 42, 211-233.

- Rogers, R.D.Incised meanders of the Río Patuca, stream piracy and landform development of the La Mosquitia, Central America,Fifteenth Caribbean Geological Conference, Kingston, Jamaica, June 29 - July 2, 1998, Articles, Field Guides and Abstracts: Contributions to Geology, Vol. 3. University of the West Indies, Kingston, 1998, pp. 92.

- Shawn P. Wright, Livio L. Tornabene and Michael S. Ramsey Remote sensing of impact craters. Impact Cratering: Processes and Products, First Edition. Edited by Gordon R. Osinski and Elisabetta Pierazzo,194-214.

- Spray, J., Elliot, B., 2010. Earth Impact Database. The Planetary and Space Science Centre, /www.passc.net/EarthlmpactDatabase/index.htmlS. 